C00-1018-1188

DEPARTMENT OF COMPUTER SCIENCE

UNIVERSITY OF ILLINOIS

RECEIVED BY DTIE OCT 281960

URBANA, ILLINOIS 61801

\title{
DYNAMIC FOCUSING AND PINCUSHION \\ CORRECTION CIRCUIT FOR THE \\ ILLIAC III DISPLAY SYSTEM*
}

by

Sergio Franco

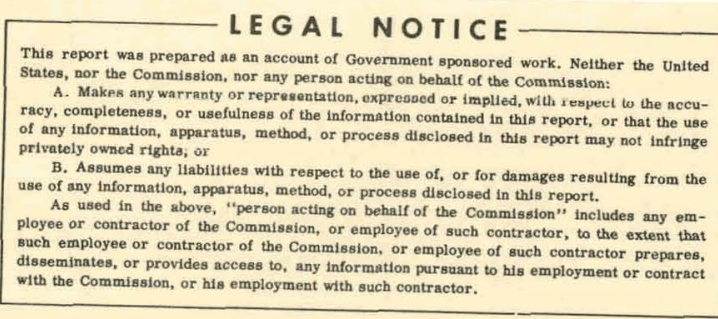

File No. 805

August 12, 1969

*Supported by Contract AT(11-1)-1018 with the U.S. Atomic Energy Commission. 


\section{DISCLAIMER}

This report was prepared as an account of work sponsored by an agency of the United States Government. Neither the United States Government nor any agency Thereof, nor any of their employees, makes any warranty, express or implied, or assumes any legal liability or responsibility for the accuracy, completeness, or usefulness of any information, apparatus, product, or process disclosed, or represents that its use would not infringe privately owned rights. Reference herein to any specific commercial product, process, or service by trade name, trademark, manufacturer, or otherwise does not necessarily constitute or imply its endorsement, recommendation, or favoring by the United States Government or any agency thereof. The views and opinions of authors expressed herein do not necessarily state or reflect those of the United States Government or any agency thereof. 


\section{DISCLAIMER}

Portions of this document may be illegible in electronic image products. Images are produced from the best available original document. 
The elecron beam length in a Cathode. Ray Tube usually is not constant, but depends on the amount of deflection of the beam itself. For a flat-faced CRT, the field required for focusing is

$$
B_{\text {focus }}=B_{\text {static }}+K\left(X^{2}+Y^{2}\right) \text {, }
$$

where $B_{\text {static }}$ represents the focusing field for the undeflected spot, $X$ and $Y$ represent deflections relative to center screen, and the term $\mathrm{K}\left(\mathrm{X}^{2}+\mathrm{Y}^{2}\right)$ represents the dynamic focus correction.

Inherent in any CRT there is a geometric distortion called "pincushion," a name which stems from the fact that a rectangular raster of deflection currents produces a figure with pointed corners and bowed-in sides. It has been shown ${ }^{l}$ that, in the case of a flat-faced CRT, this distortion can be eliminated by correcting the $\mathrm{X}$ and $\mathrm{Y}$ deflecting fields with terms proportional to $X\left(X^{2}+Y^{2}\right)$ and $Y\left(X^{2}+Y^{2}\right)$ respectively.

The above functions of $X$ and $Y$ are generated by the "Dynamic Focusing and Pincushion Correction Circuitt," whose block diagram is shown in Figure 1 .

The input signals are taken from the $X$ and $Y$ Digital-to-Analog Converters outputs, and represent voltages in the range 0 to -8.190 volts. These voltages are shifted by +4.095 volts, and then rectified, so that the correction fields are symmetrical with respect to zero deflection, corresponding to center screen.

As can be seen from Figure 2, the offsetting of the input signals is accomplished by the simple precision-resistor dividers $R 2$ and $R 8$, $R I l$ and $R I 7$ respectively.

1. Divilbiss, J.L., "Illiac III Scanner Analog Circuits", Department of Computer Science Report No. 320, University of Illinois, Urbana, Ill., (April 1969). 


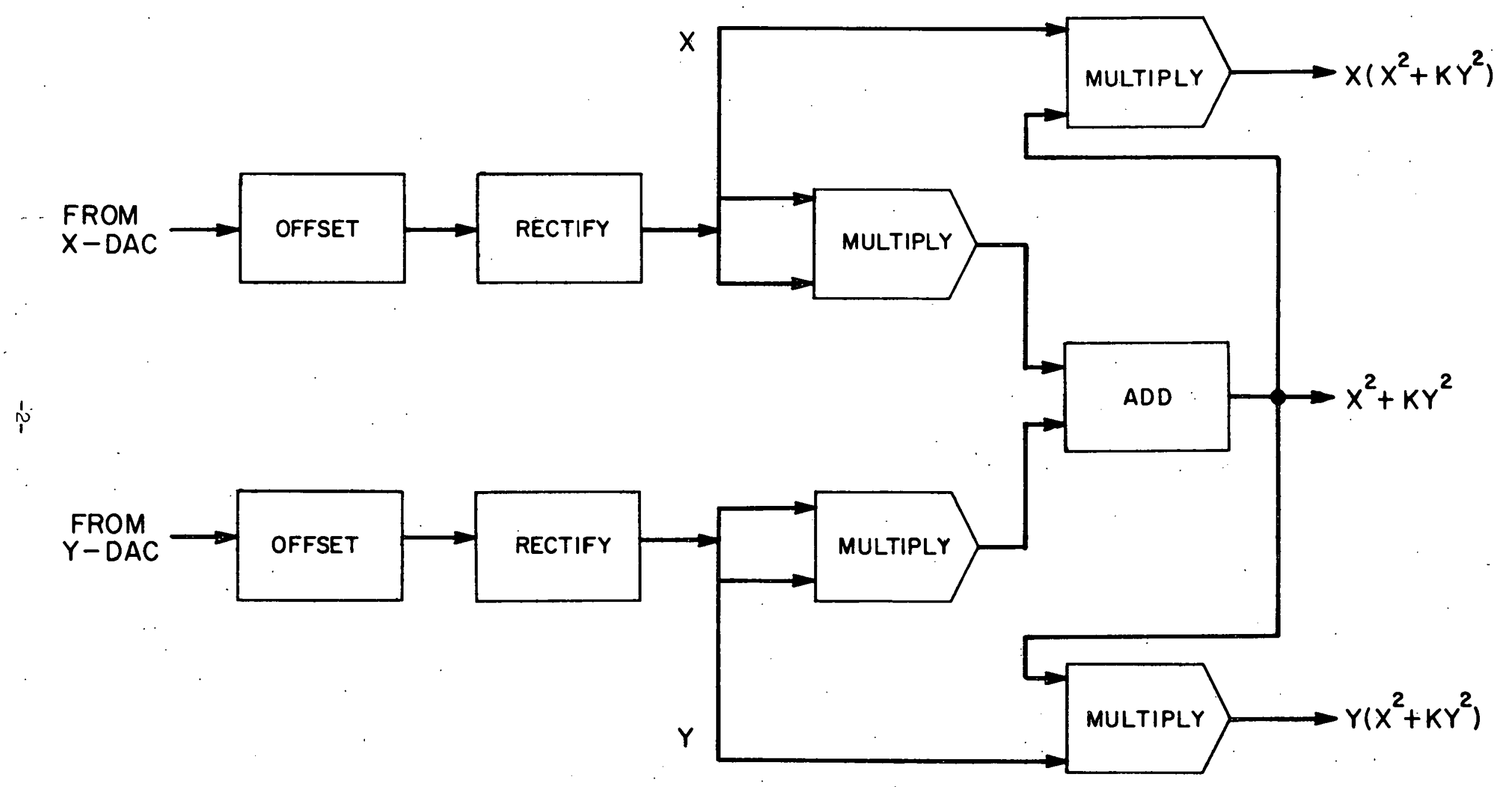

Figure I - Block Diagram for the "Dynamic Focusing and Pincushion Correction Circuit" 


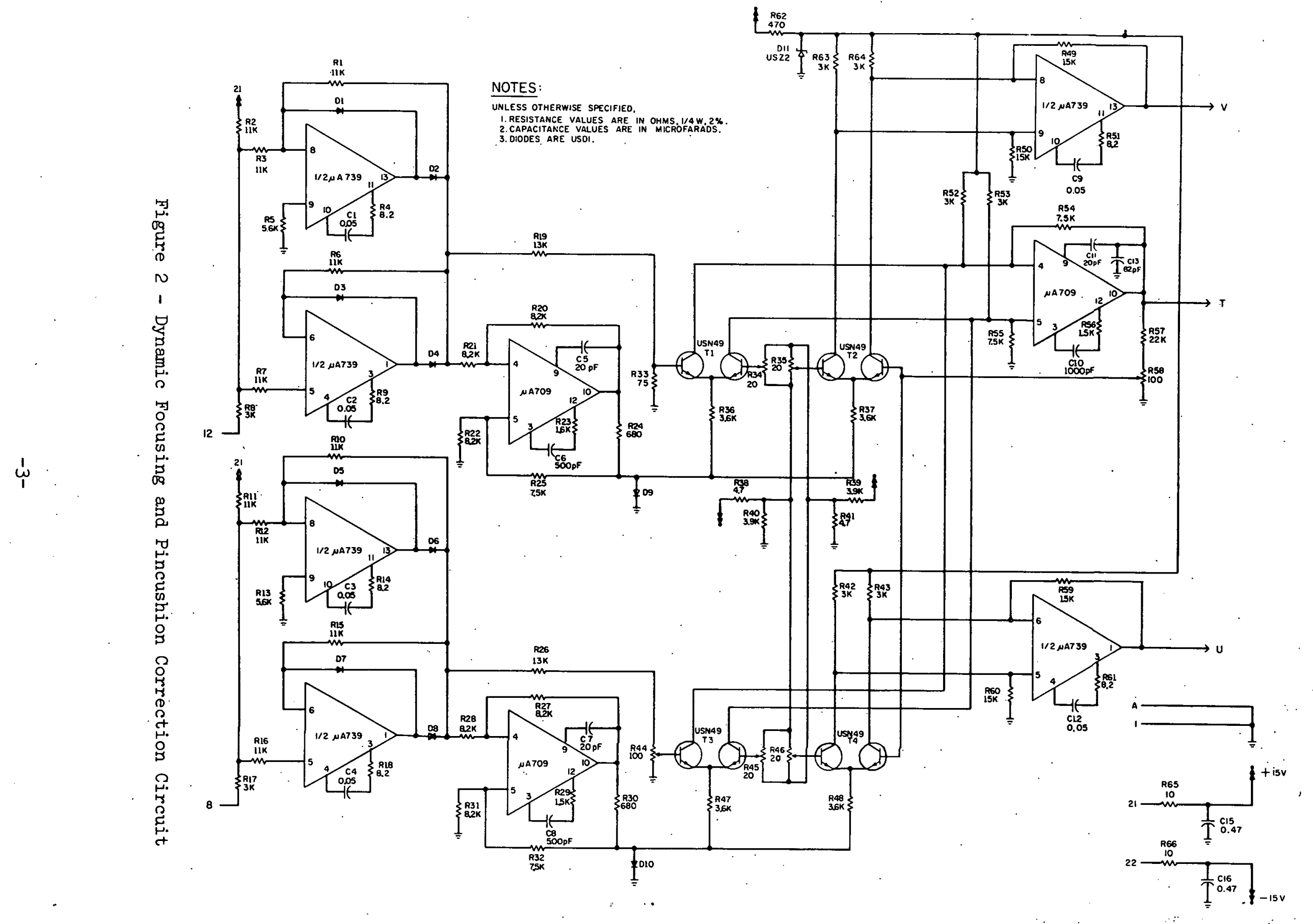


The "Rectify" circuits generate the absolute values of the offset signals; they have been designed on the basis of the idea proposed in Reference 2. This scheme allows the achievement of high accuracies with the use of only a single pair of matched resistors, namely $R I$ and $R 3$ for the X circuit; conventional ${ }^{3}$ absolute-value circuits need several matched or trimmed resistor pairs. The circuits has been realized with a $\mu$ A739 unit, which consists of two identical operational amplifiers constructed on a single silicon chip, thus allowing considerable space saving in the component layout.

The "Multiply" circuits generate an output which is proportional to the product of their two inputs. Their operation is based on the principle of the variable transconductance of matched transistor pairs, a technique now widely used in analog function generation because of its simplicity and the fact that it achieves fast response with small size and low cost.

The transconductance of a transistor may be found by differentiating the fundamental equation which relates collector current $I_{C}$ and base-emitter voltage drop $\mathrm{V}_{\mathrm{BE}}$, namely

$$
\frac{d I_{C}}{d V_{B E}}=\frac{d}{d V_{B E}} \quad\left[I_{S} \exp \left(\frac{q v_{B E}}{k T}\right)\right]=\frac{q}{k T} I_{C}
$$

where $I_{S}$ is the saturation current, $q$ the electron charge, $k$ is Boltzmann's constant and $T$ the absolute temperature. By using a pair of matched transistors with the emitters tied together, the above equation may be exploited to obtain signal multiplication as follows. Let's suppose the two transistors are initially balanced, i.e. $V_{B I}=V_{B 2}$; (see Figure 3 ) then the current $I_{E}$ supplied to the emitters will split equally between the two transistors, so that their transconductances are:

2. Smither, M.A., "Improved Absolute-Value Circuit", EEE Vol. 17; No. 3, p. 124, (March 1969).

3. "Handbook of Operational Amplifïer Applications", p. 42, Burr-Brown Research Corp., 1969. 


$$
\frac{d I_{C 1}}{d V_{B E l}}=\frac{d I_{C 2}}{d V_{B E 2}}=\frac{q}{k T}\left(I_{E} / 2\right) .
$$

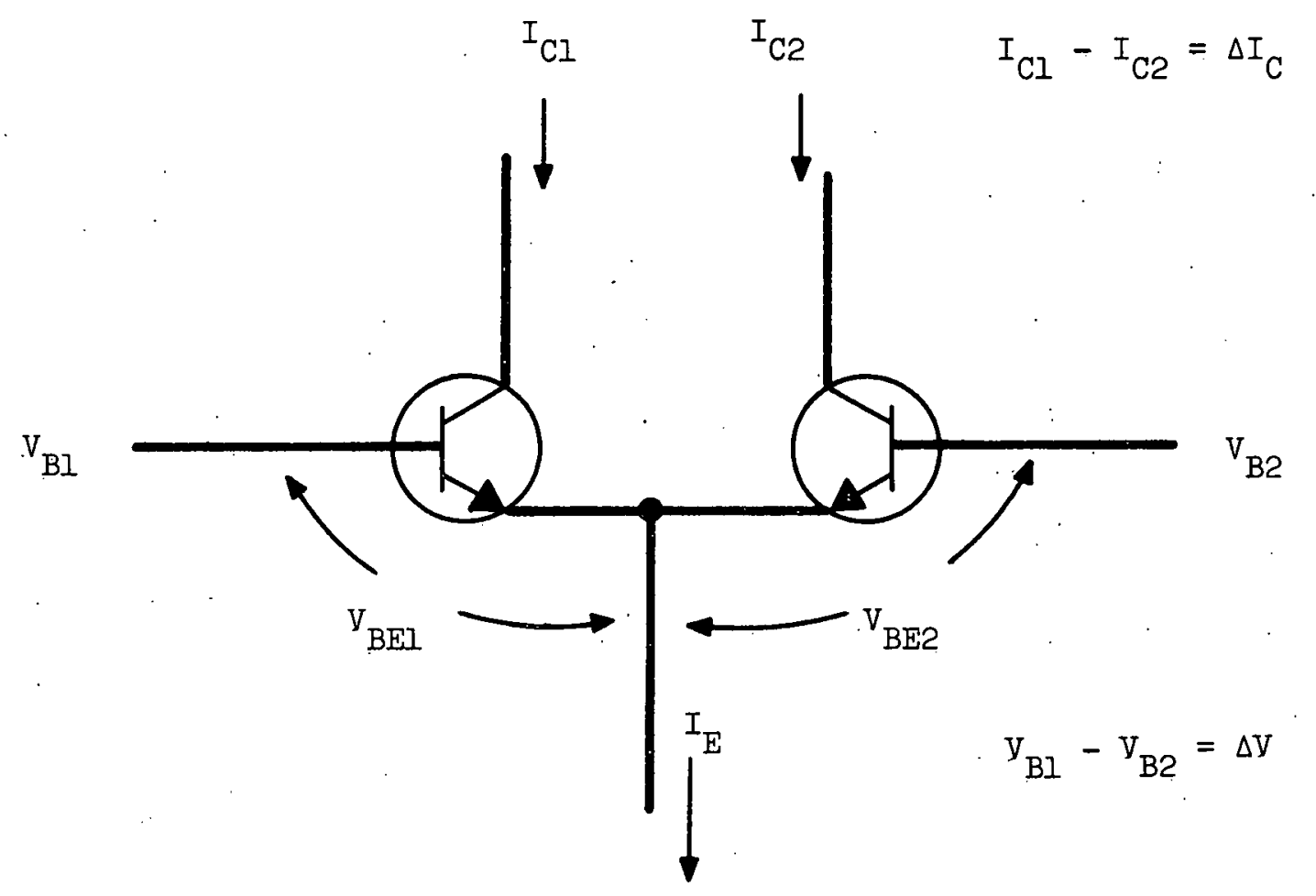

Figure 3 - Variable Transconductance Multiplier:

$$
\Delta I_{C}=\frac{q}{2 k T} \cdot I_{E} \cdot \Delta V
$$

If we now unbalance the two transistors by applying a differential input signal $d V$ between $B 1$ and $B 2$, so that $V_{B 1}=v_{B 2}+d V$, we have $d V_{B E I}-d V_{B E 2}=$ dV. Then, according to the transconductance equations, the two collector currents will vary by the amounts

$$
d I_{C l}=\frac{q}{2 k T} \cdot I_{E} \cdot d V_{B E I}
$$

and

$$
\mathrm{dI}_{\mathrm{C} 2}=\frac{\mathrm{q}}{2 \mathrm{kT}} \cdot \mathrm{I}_{\mathrm{E}} \cdot \mathrm{dV}_{\mathrm{BE} 2}
$$


respectively. If we define $d I_{C} \equiv d I_{C 1}-d I_{C 2}$, we obtain

$$
d I_{C}=\frac{q}{2 k T} \cdot I_{E} \cdot d V
$$

For small signals, the differentials may be replaced by small, finite increments, and we get

$$
\Delta I_{C}=\frac{q}{2 k T} \cdot I_{E} \cdot \Delta V
$$

so that the differential output current is proportional to the product of the common emitter current and the differential input voltage. The proportionality constant, at room temperature, is approximately equal to 19 volts $^{-1}$.

The matched transistor pairs employed in the present design are the Sprague TD101 units, which have been found to satisfy Equation (i) rather accurately in the range $I_{E} \lesssim 2 m A$ and $|\Delta V| \lesssim 15 m v$. The emitter currents to the matched pairs are supplied by the $\mu A 709$ operational amplifiers, which act as current generators. For proper operation, it follows from operational amplifier theory that the resistors of the external network must satisfy the condition (here we refer to the $\mathrm{X}$ current generator)

$$
\frac{R 2 l}{R 22}=\frac{R 20}{R 24+R 25}
$$

Then the current driven from the load is given by $i_{L}=\frac{\dot{R} 20}{R 2 I} \cdot \frac{X}{R 24} \cdot$ The above resistors have been sorted in order to satisfy Equation (2) within $0.1 \%$. Since the multipliers TI and $T 2$ have an input in common, they are driven in parallel by the same current generator. Resistors R36 and R37 have been introduced in order to compensate for mismatches between the base-emitter voltage drops of the two pairs and therefore allow the current supplied by the $\mu \mathrm{A} 709$ to split into equal parts. The two current generators have been realized by using two separate operational amplifiers, 
rather than a single $\mu \mathrm{A} 739$ unit, because of the negative swing limitations of the output stage of the latter.

The maximum value attained by $\mathrm{X}$ occurs, for instance, when the input is 0 volts, at which, for the component values of Figure 2, we have

$$
\overline{\mathrm{X}}=15 \frac{(\mathrm{R} 3\rfloor \mid \mathrm{R} 8)}{(\mathrm{R} 3 \mid \mathrm{R} 8)+\mathrm{R} 2} \approx 2.6 \text { volts. }
$$

Hence

and

$$
\begin{aligned}
& I_{E} \leq \frac{\bar{X}}{R 24} \approx 1.95 \mathrm{~mA}, \\
& \Delta V \leq \frac{\mathrm{R} 62}{\mathrm{R} 19} \overline{\mathrm{X}} \approx 15.2 \mathrm{mv},
\end{aligned}
$$

$$
\Delta I_{C} \lesssim 19 \cdot \bar{I}_{E} \cdot \overline{\Delta V} \approx 0.56 \mathrm{~mA}
$$

The trimpots $\mathrm{R} 34, \mathrm{R} 35, \mathrm{R} 45$ and $\mathrm{R} 46$ are used to adjust initial voltage offsets between the base-emitter voltage drops of the corresponding transistor pairs. $\mathrm{R} 44$ is used to compensate for possible mismatches between the transconductances of $\mathrm{Tl}$ and $\mathrm{T} 3$, and between $\mathrm{R} 24$ and $\mathrm{R} 30$. It may also be used to control the constant $K$ in the expression $X^{2}+K Y^{2}$; this adjustment may be needed in cases in which the $X$ and $Y$ radii of curvature of the $C R T$ screen are different. The various steps required for the adjustments of the trimpots are presented in the Appendix.

The circuit just described has been laid out on a single card (1018-317-00). Particular care has been used in filtering the operational amplifiers power supplies and in matching the components which are critical for the overall performance of the circuit. The transistor pairs have been selected so that the base-emitter voltage drops of TI and T2, and of T3 and T4 are matched within $0.2 \%$. Furthermore the following resistor pairs have been matched within 0.1\%: RI,R3; R2,R8; RII,R17; R21,R22; R20,(R24+R25); 
$\mathrm{R} 28, \mathrm{R} 31 ; \mathrm{R} 27,(\mathrm{R} 30+\mathrm{R} 32) ; \mathrm{R} 36, \mathrm{R} 37 ; \mathrm{R} 47, \mathrm{R} 48 ; \mathrm{R} 63, \mathrm{R} 64 ; \mathrm{R} 42, \mathrm{R} 43 ; \mathrm{R} 52, \mathrm{R} 53 ;$ R49,R50; R54,R55; R59,R60. For applications with less demanding performance, the above matching requirements can be relaxed to about $1 \%$.

The dynamic behavior of the circuit is shown in Figures 4 and 5, which represent the input and output swings for full scale transitions. It is seen that rise and fall times are less than $12 \mu \mathrm{s}$, and are limited essentially by the slew-rates of the operational amplifiers, so that if higher speeds are needed, it is necessary to use faster amplifiers. For the present application, the above speeds are more than satisfactory.

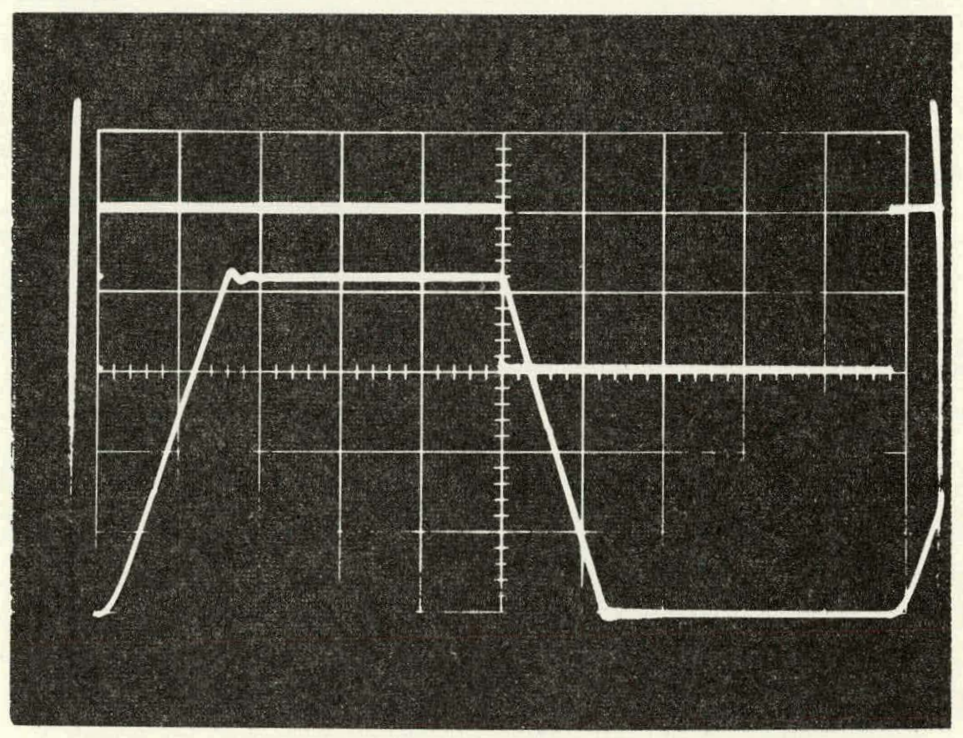

Figure 4 - Vertical: 2 volts/div., Horizontal: $5 \mu \mathrm{s} /$ div. Upper trace represents voltage signal at input terminals tied together, and ranges from -4.09 to 0 volts. Lower trace represents output signal at the $X^{2}+K_{2} 2$ terminal, and ranges from 0 to +8.4 volts approximately. 


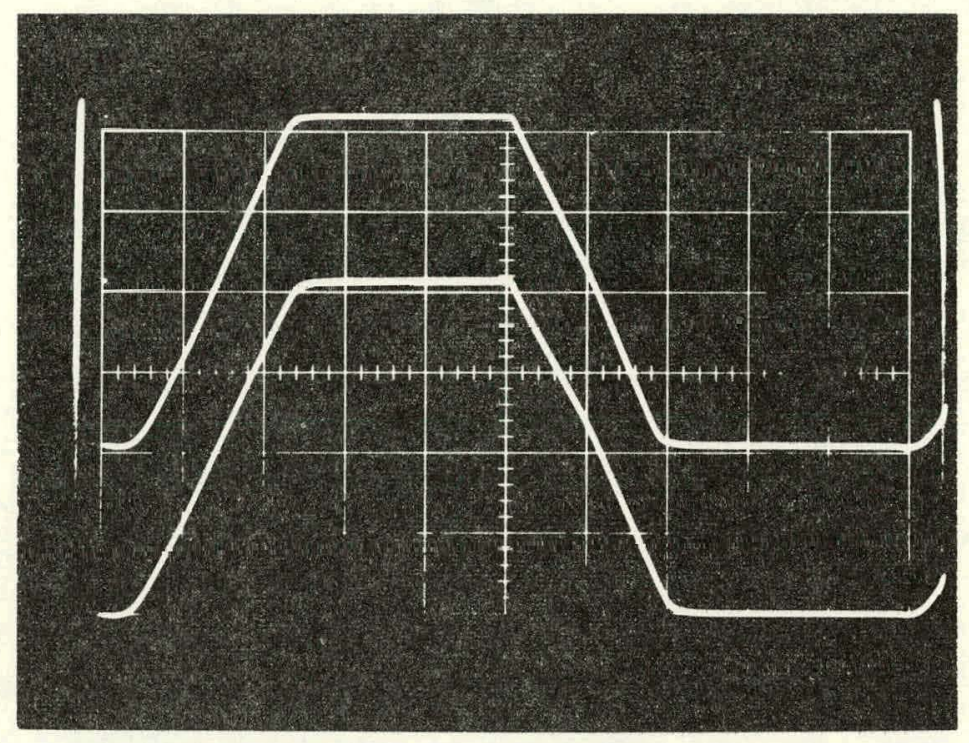

Figure 5 -Vertical: 2 volts/div., Horizontal: $5 \mu \mathrm{s} /$ div. Upper and lower traces represent signals at the $X\left(X^{2}+K Y^{2}\right)$ and $Y\left(X^{2}+K Y^{2}\right)$ outputs respectively, for input signals as in Figure 4.

The d.c. accuracy at room temperature is exhibited in Figure 6. It may be verified that the outputs, apart from an irrelevant scale factor, represent the required functions of $X$ and $Y$ within about $0.5 \%$ of full scale.

The temperature tests have shown that the Dynamic Focusing output has a temperature coefficient of about $0.25 \%$ of full scale per ${ }^{\circ} \mathrm{C}$, whereas the Pincushion Correction outputs have a coefficient twice as big. 


\begin{tabular}{cccc}
$\begin{array}{c}\text { Retifier } \\
\text { Output } \\
\mathrm{Y}\end{array}$ & $\begin{array}{c}\text { Pin T: } \\
\mathrm{X}^{2}+\mathrm{Y}^{2}\end{array}$ & $\mathrm{Y}\left(\mathrm{X}^{2}+\mathrm{Y}^{2}\right)$ & $\begin{array}{c}\text { Pin V } \\
\mathrm{X}\left(\mathrm{X}^{2}+\mathrm{Y}^{2}\right)\end{array}$ \\
\hline & & & \\
0.002 & +0.001 & -0.002 & +0.002 \\
0.100 & 0.005 & +0.001 & 0.002 \\
0.200 & 0.021 & 0.006 & 0.002 \\
0.400 & 0.091 & 0.023 & 0.002 \\
0.600 & 0.208 & 0.057 & 0.002 \\
0.800 & 0.377 & 0.123 & 0.002 \\
1.000 & 0.590 & 0.235 & 0.002 \\
1.200 & 0.854 & 0.402 & 0.002 \\
1.400 & 0.160 & 0.635 & 0.002 \\
1.600 & 1.516 & 0.940 & 0.002 \\
1.800 & 1.91 & 1.326 & 0.002 \\
2.000 & 2.35 & 1.81 & 0.002 \\
2.200 & 2.84 & 2.41 & 0.002 \\
2.400 & 3.37 & 3.12 & 0.002 \\
2.600 & 3.95 & 3.94 & 0.002 \\
2.700 & 4.25 & 4.40 & 0.002 \\
& & &
\end{tabular}

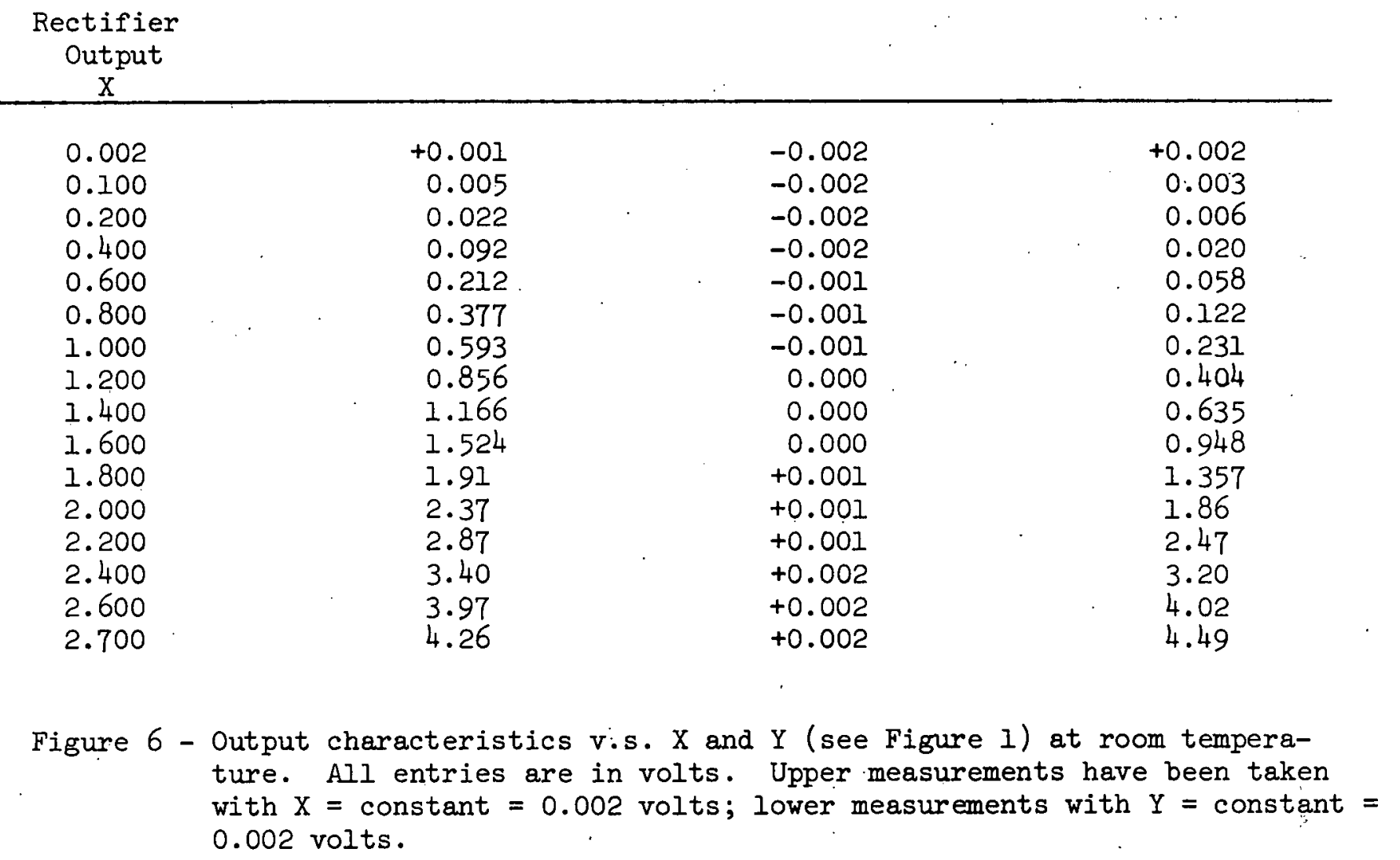


APPENDIX

Adjustment of 1018-317-00 Card

In the following procedure, the offsets between base-emitter voltage drops of transistors belonging to the same matched pair are adjusted to 0 volts when $I_{E}$ assumes its mid-range value, i.e. I mA approximately. By convention, $v_{i}$ will denote the voltage at pin $i$.

1) Set $\mathrm{R} 34, \mathrm{R} 35, \mathrm{R} 45, \mathrm{R} 46$ and $\mathrm{R} 58$ to midrange approximately. Set $\mathrm{R} 44$ to $3 / 4$. of its range towards ground.

2) Set $V_{8}=V_{12}=-4.096$ volts. Tie DVM to pin U. Manually connect a $13 \mathrm{~K}$ resistor between emitter of $\mathrm{T} 4$ and -15 volts. Adjust $\mathrm{R} 46$ until $\mathrm{V}_{\mathrm{U}}=0$ volts.

3) $V_{8}$ and $V_{12}$ as in step 2. Tie DVM to pin V. Manually connect a $13 \mathrm{~K}$ resistor between emitter of $\mathrm{T} 2$ and -15 volts. Adjust $\mathrm{R} 35$ until $\mathrm{V}_{\mathrm{V}}=0$ volts.

4) $V_{8}$ and $V_{12}$ as in step 2. Tie DVM to pin T. Manually connect a $13 \mathrm{~K}$ resistor between emitter of $\mathrm{TI}$ and -15 volts. Adjust $\mathrm{R} 34$ until $\mathrm{V}_{\mathrm{T}}=0$ volts.

5) Leave $\mathrm{V}_{8}$ as in step 2, set $\mathrm{V}_{12}=0$ volts. Measure $\mathrm{V}_{\mathrm{T}}$ and let $\mathrm{V}^{*}$ be the value of the reading.

6) $v_{8}$ and $v_{12}$ as in step.2. Manually connect a $13 \mathrm{~K}$ resistor between emitter of $\mathrm{T} 3$ and -15 volts. Adjust $\mathrm{R} 45$ until $\mathrm{V}_{\mathrm{T}}=0$ volts.

7) Set $v_{8}=0$ volts, $v_{12}=-4.096$ volts. Adjust R44 until $\mathrm{V}_{\mathrm{T}}=\mathrm{K} \cdot \mathrm{V}^{*}$, where $\mathrm{K}$ is the constant appearing in the expression $\mathrm{X}^{2}+\mathrm{KY}^{2}$ (usually $\mathrm{K}=1$ ).

8) Repeat step 6; if $\mathrm{R} 45$ does not need to be adjusted, then all adjustments are finished; else adjust R45 and go to step 7 , etc. 